\title{
The Immunosuppressive Significance of Lactate Dehydrogenase (LDH) Blood Levels in Metastatic Cancer Patients
}

ISSN: 2637-773X

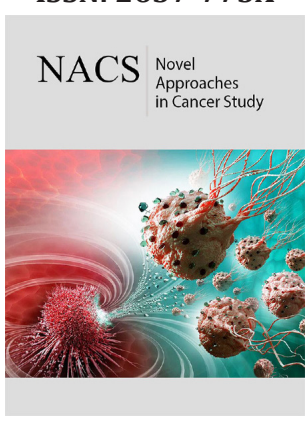

*Corresponding author: Paolo Lissoni, Institute of Biological Medicine, Milan, Italy

Submission: 留 February 25, 2020

Published: : March 05, 2020

Volume 4 - Issue 2

How to cite this article: Paolo Lissoni, Giorgio Porro, Gianmaria Borsotti, Alessio Tosatto, Giuseppe Di Fede. The Immunosuppressive Significance of Lactate Dehydrogenase (LDH) Blood Levels in Metastatic Cancer Patients. Nov Appro in Can Study.4(2). NACS.000583.2020. DOI: 10.31031/NACS.2020.04.000583

Copyright@ Paolo Lissoni. This article is distributed under the terms of the Creative Commons Attribution 4.0 International License, which permits unrestricted use and redistribution provided that the original author and source are credited.
Paolo Lissoni*, Giorgio Porro, Gianmaria Borsotti, Alessio Tosatto and Giuseppe Di Fede

Institute of Biological Medicine, Milan, Italy

\begin{abstract}
In addition to the well-known negative prognostic significance of the abnormally high blood levels of lactate dehydrogenase LDH in most neoplasms, more recently it has been shown that the evidence of abnormally low values of lymphocyte-to-monocyte ratio (LMR) may also predict a poor prognosis in human tumors. On these bases, a preliminary study was carried out to evaluate which relationship may occur between LMR and LDH levels in metastatic cancer patients. The study included 100 metastatic solid tumor patients. Breast, lung and gastrointestinal tract tumors were the neoplasms most frequent in our patients. Patients with high LDH levels showed significantly lower values of LMR. Since the occurrence of low LMR values is the expression of an immunosuppressive status, the association between LDH high levels and low LMR values would suggest that LDH may predict a poor prognosis in metastatic cancer not only by reflecting tumor extension, but also for its potential immunosuppressive status.
\end{abstract}

Keywords: Biomarkers; Immunosuppression; Lactate dehydrogenase; Lymphocyte to monocyte ratio; Tumor markers

\section{Introduction}

Lactate dehydrogenase (LDH) is a metabolic enzyme expressed by several tissues, which catalyzes the interconversion of pyruvate and lactate during glycolysis and gluconeogenesis [1]. Many cancers have higher levels of LDH than normal tissues [1,2]. Finally, the evidence of increased LDH serum levels have appeared to play a negative prognostic significance in terms of both survival time [1] and resistance to chemotherapy and radiotherapy [2]. It is also known that cancer cells are characterized by an enhanced glucose uptake, glycolysis, and lactate production. A large amount of pyruvate in cancer cells is converted into lactate by LDH [2]. Moreover, the excess of lactate transported out of the cytoplasm may influence the microenvironment and promote interactions between cancer cells and stromal cells with their tumor growth factors, which allows an increased cell invasion and migration [13]. LDH was one of the first tumor biomarkers provided by prognostic significance to be introduced into clinical practice. More recentlly, another fundamental biomarker has been identified, consisting of the lymphocyte-to-monocyte ratio (LMR), since the evidence of abnormally low values of LMR has appeared to predict a poor prognosis, being associated with a lower survival and a less response to the various antitumor therapies [4]. This finding is not surprising by taking into consideration that lymphocytes are the main cells involved in tumor cell destruction [5,6], and that monocyte count has been proven to reflect cancerrelated inflammatory status and the activation of the macrophage system $[7,8]$, as well as tumor macrophage infiltration and activation of the regulatory T lymphocytes [9], which represent the main cells reponsible for the suppression of the antitumor immunity [10-12]. Generally, the negative prognostic significance of LDH is explained in terms of a correlation to tumor mass and extension [1,2]. However, because of the influence of lactate on the metabolic activity of most cells, including lymphocytes, the evidence of abnormally high levels of LDH could also induce an altered immune function, producing an immunosuppressive status. On these bases, a preliminary study was performed, in an attempt to evaluate which relationships may exist between LDH serum levels and LMR in a group of metastatic cancer patients. 


\section{Materials and Methods}

The study included 100 consecutive patients affected by metastatic solid neoplasms. Eligibility criteria were, as follows: histologically proven solid neoplasm, metastatic disease, measurable lesions, no double tumor, and no chronic therapy with corticosteroids, because of their inhibitory influence on lymphocyte generation. The clinical characteristics of patients are reported in Table 1. Venous blood samples were collected in the morning after an over-night fast. Serum levels of LDH were measured by an enzyme immunoassay and commercial kits. Normal values obtained in our laboratory (95\% confidence limits) were below 250U/L. Data were reported as mean +/-SE, and statistically analyzed by the Student's t test, coefficient of correlation and chi-square test, as appropriate.

Table 1: Clinical characteristics of 100 metastatic cancer patients.

\begin{tabular}{|c|c|}
\hline Characteristics & $\mathbf{N}$ \\
\hline $\mathrm{M} / \mathrm{F}$ & $58 / 42$ \\
\hline Median Age & $66(28-83)$ \\
\hline \multicolumn{2}{|l|}{ Tumor histotype } \\
\hline Breast cancer & 32 \\
\hline Lung cancer & 26 \\
\hline Colorectal cancer & 14 \\
\hline Gastric cancer & 11 \\
\hline Pancreatic adenocarcinoma & 8 \\
\hline Gynecologic tumors & 7 \\
\hline Bladder cancer & 2 \\
\hline \multicolumn{2}{|l|}{ Metastasis sites } \\
\hline Soft tissues & 5 \\
\hline Bone & 10 \\
\hline Lung & 31 \\
\hline Liver & 22 \\
\hline Liver + lung & 16 \\
\hline Serouses & 9 \\
\hline Brain & 7 \\
\hline
\end{tabular}

\section{Result}

LDH and LMR mean values are reported in Table 2. Abnormally high serum levels of LDH and abnormally low values of LMR were respectively observed in 32 (32\%) and in 36 (36\%) cancer patients. LMR mean values observed in patients with high LDH concentrations were significantly lower than those found in patients with normal LMR values $(\mathrm{P}<0.05)$. On the other hand, patients with abnormally low values of LMR had LDH mean levels significantly higher than patients with normal LMR $(\mathrm{P}<0.05)$, even though no significant correlation was seen between LMR values and LDH serum concentrations $(r=-0.3)$.
Table 2: Mean(+/SE) values of LMR and LDH serum levels in 100 metastatic cancer patients.

\begin{tabular}{|c|c|}
\hline Parameter & \\
\hline LDH $(\mathrm{U} / \mathrm{L})$ & LMR \\
\hline Normal values $(n=68)$ & $4.5+/-0.3^{*}$ \\
\hline High values $(n=32)$ & $2.6+/-0.5$ \\
\hline LMR & $\mathrm{LDH}$ \\
\hline Normal values $(n=64)$ & $238+/-31 \mathrm{U} / \mathrm{L}$ \\
\hline Low values $(n=36)$ & $389+/-41^{* *}$ \\
\hline \multicolumn{2}{|c|}{$* \mathrm{P}<0.05$ vs high LDH levels; ${ }^{* *} \mathrm{P}<0.05$ vs normal LMR values } \\
\hline
\end{tabular}

\section{Discussion}

This preliminary study, by showing higher levels of LDH in patients with abnormally low values of LMR, would suggest that LDH blood concentrations does not reflect only tumor mass and extension, but also cancer-related immunosuppressive status, because of the possible negative influence of lactate on lymphocyte proliferation and functions. This finding could also explain the lower efficacy of cancer immunotherapy with IL-2 [13] or antiPD1 monoclonal antibodies [14] in the presence of abnormally high levels of LDH. In any case, further studies will be necessary to establish which lymphocyte subset may be particularly influenced by LDH levels, including TH1 and T reg lymphocytes. Moreover, successive studies will be required to establish whether the association of low LMR values with high levels of LDH may furtherly enhance the already negative prognostic significance of LDH levels themselves.

\section{References}

1. Liu R, Cao J, Gao X, Zhang J, Wang L, et al. (2016) Overall survival of cancer patients with serum lactate dehydrogenase greater than $1000 \mathrm{U} / \mathrm{L}$. Tumor Biol 37(10): 14083-14088.

2. Zhao D, Xiong Y, Lei QY, Gual KL (2013) LDH-A acetylation: implication in cancer. Oncotarget 4(6): 802-803.

3. Jurisic V, Radenkovic S, Konjevic G (2015) The actual role of LDH as tumor marker, biochemical and clinical aspects. Adv Exp Med Biol 867: 115-124.

4. Eo WK, Chang HJ, Kwon SH, Koh SB, Kim Yo, et al. (2016) The lymphocyteto-monocyte ratio predicts patient survival and agressiveness of ovarian cancer. J Cancer 7(3): 289-296.

5. Riesco A (1970) Five-year cancer cure: Relation to total amount of peripheral lymphocytes and neutrophils. Cancer 25(1): 135-140.

6. Grimm EA, Mazumder A, Zhang HZ, Rosenberg SA (1982) Lymphokineactivated killer cell phenomenon. J ExpMed 155(6): 1823-1841.

7. Mantovani A, Allavena P, Sica A, Balkwill F (2008) Cancer-related inflammation. Nature 454(7203): 436-444.

8. Grivennikov SI, Greten FR, Karim M (2010) Immunity, inflammation and cancer. Cell 140(6): 883-899.

9. Lissoni P, Messin G, Rovelli F, Vigoré L, Lissoni A, et al. (2018) Low lymphocyte-to-monocyte ratio is associated with an enhanced regulatory $\mathrm{T}$ lymphocyte function in metastatic cancer patients. Int J RecAdv Multi Res 5: 3353-3356. 
10. Kim R, Emi M, Tanabe K, Uchida Y, Toge T (2004) The role of Fas-ligand and transforming growth factor-beta in tumor progression. Cancer 100(11): 2281-2291.

11. Antony PA, Restito NP (2005) CD4+CD25+ T regulatory cells, immunotherapy of cancer and interleukin-2. J Immunother 28(2): 120 128.

12. Zou W (2006) Regulatory T cells, tumor immunity and immunotherapy. Nat Rev Immunol 6(4): 295-307.
13. Rosenberg SA (1992) The immunotherapy and gene therapy of cancer. Cancer Res 51(18 Suppl): 5074s-5079s.

14. Ashwell S, Janetka JW, Zabludoff S (2008) Keeping checkpoint kinase in line: new selective inhibitors in cinical trials. Exp Opin Invest Drugs 17(9): 1331-1340.

\section{For possible submissions Click below:}

